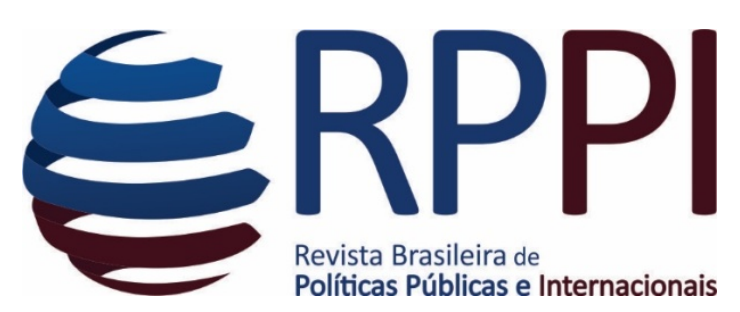

Data de recebimento: 23/10/2017

Data de aceite: 05/06/2018

Organização: Programa de Pós-Graduação em

Gestão Pública e Cooperação Internacional

(PGPCI/UFPB)

Avaliação: Por Pares.

\title{
Exercício de análise de políticas públicas: o Programa Estratégico para o Empreendedorismo e Inovação do Governo de Portugal (Programa +e+i)
}

\section{Exercise of analysis of public policies: the Strategic Program for Entrepreneurship and Innovation of the Government of Portugal (Program $+\mathbf{e}+\mathbf{i}$ )}

\author{
Tiago Hideki Niwa \\ Universidade Tecnológica Federal do Paraná - UTFPR e Instituto Universitário de Lisboa - \\ ISCTE-IUL \\ E-mail: tiagoniwa@gmail.com
}

Resumo: O exercício de análise de políticas públicas busca esclarecer o desenho e o processo de uma determinada medida de política. Assim, o presente artigo apresenta a análise do Programa Estratégico para o Empreendedorismo e a Inovação (Programa +e+i), do XIX Governo Constitucional de Portugal. Para tanto, realiza-se a análise por meio do modelo das etapas do ciclo político, quais sejam: definição do problema; agendamento político; formulação da medida de política; concretização (legitimação e implementação); e a avaliação e mudança. Os resultados da pesquisa são apresentados por meio de uma relação dos pontos positivos e negativos da política analisada.

Palavras-chaves: ciclo das políticas públicas; inovação e empreendedorismo; pesquisa e desenvolvimento.

\begin{abstract}
The public policy analysis exercise seeks to clarify the design and process of a given policy measure. Thus, this article presents the analysis of the Strategic Program for Entrepreneurship and Innovation (Program $+\mathrm{e}+\mathrm{i}$ ), of the XIX Constitutional Government of Portugal. To do so, the analysis is performed through the policy cycle theory, which are: problem definition; agenda-setting; policy's formulation; concretion (legitimation and implementation); and evaluation and change. The results of the research are presented through a list of the positive and negative points of the analyzed policy.
\end{abstract}

Keywords: policy cycle; innovation and entrepreneurship; research and development. 
NIWA, Tiago Hideki. Exercício de análises de políticas públicas: o Programa Estratégico para o Empreendedorismo e Inovação do Governo de Portugal (Programa +e+i).

\section{Introdução}

O agendamento político, acerca de assuntos relacionados ao empreendedorismo e à inovação, é globalmente reconhecido para induzir o desenvolvimento da economia e do bemestar da sociedade. No entanto, acredita-se que muitos debates públicos concernentes a essa temática trazem abstrações na sua aplicabilidade e na concretude de suas propostas.

Nesse sentido, para analisar a necessidade de investimento em inovação de um país, especialmente em momentos de crise econômica, faz-se valioso identificar e analisar modelos de investimento em inovação bem sucedidos em outras economias e, em seguida, desenvolver ainda mais o investimento atual em Portugal relacionada com o contexto da União Europeia (UE)(Gibson \& Naquin 2011, p. 1299).

Por isso, embora o agendamento do empreendedorismo e da inovação seja essencial para a atualidade dos setores econômicos frente aos acontecimentos vigentes, percebe-se que a construção, implementação e concretização das mesmas devem resultar em concretos benefícios à economia e à sociedade.

A imersão nos complexos temas relacionados ao “empreender” e ao “inovar” direciona a uma análise difusa de políticas públicas a partir da transferência de experiências e realizações nesse sentido, observando-se o incrementalismo de medidas prósperas em diversas esferas. Ademais, os processos das políticas públicas podem ser considerados como constantes evoluções, cujo ponto de partida pode estar situado em qualquer momento histórico (Hill 2013, p. 155).

Assim, no que concerne ao sistema empreendedor e inovativo de Portugal, verifica-se o aumento da preocupação e no investimento direto nessas áreas, especialmente em razão da colocação não favorável do país como economia da inovação(Gibson \& Naquin 2011, p. 1302).Portanto, dentro da perspectiva do Governo de Portugal em incentivar ações para o desenvolvimento e a competitividade da economia nacional, analisa-se o Programa Estratégico para o Empreendedorismo e a Inovação (Programa +e+i), implementado pelo XIX Governo Constitucional, enquanto exercício de análise de política pública.

Revista Brasileira de Políticas Públicas e Internacionais, v.3, n.2, Dezembro/2018, pp. 29-58. 
NIWA, Tiago Hideki. Exercício de análises de políticas públicas: o Programa Estratégico para o Empreendedorismo e Inovação do Governo de Portugal (Programa +e+i).

\section{Metodologia}

A análise da política pública revela-se em uma investigação exploratória e descritiva, de abordagem qualitativa, utilizando-se de técnicas de documentação indireta (pesquisa documental indireta e bibliográfica)(Lakatos \& Marconi, 2010).

John Kingdon (1995, pp. 2-3) afirma que a elaboração de políticas públicas pode ser simplificada como um conjunto de processos, incluindo ao menos: a) a definição da agenda política; b) a especificação de alternativas a partir da qual uma escolha deve ser feita; c) a escolha entre as alternativas específicas, como em uma votação legislativa ou uma decisão presidencial; e d) a implementação da decisão.

Já Dye (2011, p. 29) preleciona acerca do modelo teórico do ciclo político nas seguintes etapas: a) identificação do problema; b) agendamento da política; c) formulação; d) legitimação; e) implementação; e f) avaliação da política pública.

Para Kraft e Furlong (2009, p. 72-87), o modelo de processo político pode ser dividido nas seguintes etapas: a) definição do problema e agendamento; b) formulação da política pública; c) legitimação; d) implementação; e) avaliação; e f) mudança.

Portanto, a explicação acerca das etapas do ciclo da formação de políticas públicas é encontrada em inúmeros autores, cada qual com suas peculiaridades próprias, embora com o sentido e significações muito próximas. E para efeitos conceituais das etapas neste estudo, adotarse-á a visão de Kraft \& Furlong (2009), visto que sintetizam de forma didática o modelo teórico do ciclo político.

\section{O problema político-econômico e o Programa +e+i}

O Programa +e+i procura instigar o empresariado e a sociedade civil para a inovação e à melhoria da competitividade da economia nacional. De acordo com a página oficial do Programa

Revista Brasileira de Políticas Públicas e Internacionais, v.3, n.2, Dezembro/2018, pp. 29-58. 
NIWA, Tiago Hideki. Exercício de análises de políticas públicas: o Programa Estratégico para o Empreendedorismo e Inovação do Governo de Portugal (Programa +e+i).

$+\mathrm{e}+\mathrm{i}$, os fatores que levaram o Governo de Portugal a instituir o Programa foram, principalmente: a necessidade de recuperação econômica devido às dificuldades estruturais; a falta de retornos econômicos dos investimentos em Investigação \& Desenvolvimento (I\&D); necessidade de soluções de financiamento de novos projetos; carência de intervenção prioritária em questões de empreendedorismo além do campo da ciência e da investigação; e as referências da estratégia Europa2020, e respectiva iniciativa Innovation Union, para o desenvolvimento de políticas em inovação em Portugal para os próximos anos(Portugal, 2015).

Em montantes gerais, o Programa de Competitividade e Inovação (CIP) eo Instituto Europeu de Inovação e Tecnologia (EIT), do Horizonte 2020,possuem o valor de investimento na importância de 80 mil milhões de euros do Programa de Pesquisa e Inovação da União Europeia (UE). O investimento procura, no período de 2014 a 2020, reduzir a distância entre a inovação e o mercado por meio de três pilares principais: a excelência da ciência, a liderança industrial e mudanças sociais(Crispim et al. 2014, p. 88).

O aumento do desemprego combinado à recessão econômica, sentida nos países europeus, coincidiu com a evolução da teoria econômica que revela a interação entre a inovação tecnológica e o desenvolvimento econômico. Inclusive a OCDE indicava a necessidade de políticas em ciência e tecnologia como soluções para um possível crescimento econômico (Brandão 2015, p. 4).

Assim, acredita-se que o Programa $+\mathrm{e}+\mathrm{i}$ alia as noções de empreendedorismo e inovação, a partir de seus conceitos originários e envolvidos em teorias econômicas vigentes. O empreendedorismo, sobretudo com a contribuição de Richard Cantillon, no século XVII, e, igualmente a Jean-Baptiste Say, teve originária repercussão em várias áreas do conhecimento. Mas foi com Schumpeter que houve maior projeção do empreendedorismo, quando o relacionou à inovação. Dessarte, outros estudiosos apresentaram suas contribuições ao empreendedorismo, tais como Clark, Higgins, Baumol, Schloss, Leibenstein, Knight, Hoselitz, Casson, Kirzner, entre outros (Filion 1999, p. 6-7).

Revista Brasileira de Políticas Públicas e Internacionais, v.3, n.2, Dezembro/2018, pp. 29-58. 
NIWA, Tiago Hideki. Exercício de análises de políticas públicas: o Programa Estratégico para o Empreendedorismo e Inovação do Governo de Portugal (Programa +e+i).

Portanto, as questões de agendamento e definição do problema a serem tratadas na análise e desenho da referida política pública, podem ser consubstanciadas pelos debates públicos e pela formação da arena política sobre a relação entre a ciência, tecnologia e inovação e a correlação imediata ao desenvolvimento econômico e social. Por isso, o problema a ser investigado trata-se de como compreender, estatística e reflexivamente, as propriedades do Programa +e+i em consonância com os indicadores em empreendedorismo e inovação em Portugal?

\section{Do agendamento da política pública de inovação para o desenvolvimento em Portugal}

O agendamento político trata-se de uma etapa de como os problemas são compreendidos, definidos, destacados e colocados na agenda política (Kraft \& Furlong 2009, p. 73). No que tange ao agendamento para a formulação de políticas públicas de incentivo à inovação e ao empreendedorismo, acredita-se que o aumento dessas discussões auxilia na preocupação e no respectivo aumento em investimentos e melhorias aos setores produtivos em consonância com as instituições de Ciência, Tecnologia e Inovação (CT\&I).

Por essa razão, o Governo de Portugal, procurando também responder à estratégia Europa2020, instituiu o Programa Estratégico para o Empreendedorismo e a Inovação (Programa $+\mathrm{e}+\mathrm{i}$ ) (Portugal, 2015), a fim de integrar diversas ações nessa seara para o desenvolvimento econômico e social.

A partir do panorama originário do agendamento da política pública, faz-se necessário demonstrar a formulação das medidas de políticas a fim de fornecer subsídios para o produto da política pública, e sua respectiva concretização ou implementação. Assim, infere-se que os dados da Organização para a Cooperação e Desenvolvimento Econômico (OCDE), União Europeia (InnovationScoreboard), e do Pordata (Base de Dados Portugal Contemporâneo) e demais fontes bibliográficas e de outros dados disponíveis, são ferramentas importantes para o exercício de análise.

No que tange à avaliação das medidas da política pública é essencial verificar as eventuais mudanças e possíveis melhorias ou ajustes para o início de um novo ciclo político, podendo-se Revista Brasileira de Políticas Públicas e Internacionais, v.3, n.2, Dezembro/2018, pp. 29-58. 
NIWA, Tiago Hideki. Exercício de análises de políticas públicas: o Programa Estratégico para o Empreendedorismo e Inovação do Governo de Portugal (Programa +e+i).

repetir as etapas (considerando os feedbacks), e averiguando os atendimentos às demandas sociais e econômicas pelas quais o Programa +e+i foi implementado. Trata-se em verificar se os objetivos e metas foram atingidos (Kraft \& Furlong 2009, p. 85).

A fim de melhorar o Plano de ação para a Inovação, ativando-se o setor público como principal promotor, a Comissão Europeia (2004) chamou a atenção dos Estados-Membros para a necessidade de melhorar a governança das políticas em inovação (Laranja 2012, p. 655).

Difunde-se, hodiernamente, que os agentes econômicos e sociais e a formação de redes são cruciais para o aprimoramento das atividades produtivas, especialmente pelo desenvolvimento e transferência de tecnologias, a mobilização de recursos humanos, e à estruturação e aquisição de informações sobre o ambiente. A noção de "rede", portanto, pode ser considerada a base de diversos pontos de vista da inovação, o que se revela, inclusive, na interação e cooperação entre a indústria, o conhecimento (Universidades) e o governo (Modelo da Hélice Tríplice de Etzkowitz e Leydesdorff) (Marques et al. 2006, p. 537).

Vale informar que o lançamento do Plano Tecnológico 2005 a 2009 (TP) levou à criação de uma rede interministerialsob a coordenação de um novo gabinete: o Gabinete de Coordenação da Estratégia de Lisboa e do Plano Tecnológico (CNELPT), reportando-se diretamente ao Primeiro Ministro. Ainda, houve a criação de um Conselho Consultivo, permitindo maior participação de empresas e outros setores da sociedade. Por isso, o Plano Tecnológico pode ser considerado como um caso interessante, pois desconstrói estruturas corporativistas e a dependência de estruturas verticais, removendo algumas barreiras entre a relação da política com a ciência, investigação e inovação (Laranja 2012, p. 655). Ademais, é importante destacar a governança das políticas de inovação, que é geralmente associada ao processo pelo qual as políticas são formuladas, selecionadas, implementadas, monitoradas e substituídas(Laranja 2012, p.656).

O Bayh-Dole Act, de 1980, nos Estados Unidos da América, pode ser considerado com uma das primeiras políticas de inovação para impulsionar a economia, procurando integrar as universidades, investigações do governo e desenvolvimento de inovações procurando resultados

Revista Brasileira de Políticas Públicas e Internacionais, v.3, n.2, Dezembro/2018, pp. 29-58. 
NIWA, Tiago Hideki. Exercício de análises de políticas públicas: o Programa Estratégico para o Empreendedorismo e Inovação do Governo de Portugal (Programa +e+i).

econômicos. Essa política foi adaptada e adotada por diversos países, apresentando resultados positivos em relatórios de governo sobre a relação do empreendedorismo e a inovação. Percebese, ainda, que essa política adequa-se às economias em desenvolvimento, ou países em situação de crise econômica, visto que políticas de inovação e de investimentos são necessários para aprimorar as economias nacionais (Gibson \& Naquin 2011, p. 1300).

A realidade de Portugal, no que concerne ao agendamento da política pública, pode ser bem retratada pelo trabalho de Laranja (2012, p. 659), que demonstra a governança das políticas públicas em inovação em Portugal. O ponto de partida de seu artigo é o questionamento da OCDE, em 1986, que diz: "why does the history of Science and technology in Portugal give the impression of na unfinished symphony?”.

A política pública que revela a interação entre a inovação e o conhecimento para com o desenvolvimento econômico, na representação do empreendedorismo, possui algumas premissas. Nota-se que a informação e o conhecimento, desenvolvidos e presentes nos recursos humanos, devem se integrar aos aspectos administrativos e organizacionais de uma empresa ou de uma instituição (Gibson \& Naquin 2011, p. 1303).

A realidade da estruturação das políticas de inovação, em Portugal, embora não tenha havido mudanças recentes significativas, pode ser identificada e demonstrada, de acordo com Laranja (2012, p. 659), em três fases distintas do Governo Português.

Na primeira fase, a partir do final dos anos 1960 até meados dos anos 1980, pouco antes de Portugal aderir à UE, as políticas de inovação eram essencialmente políticas de investigação e foram considerados como um subconjunto de políticas de desenvolvimento econômico e social mais gerais (Figura 1). Na época, a Junta Nacional de Investigação Científica e Tecnológica (JNICT), criada em 1967, para coordenar as políticas setoriais para a I\&D, foi centrada na recepção de estatísticas de I\&D para a OCDE, promovendo o financiamento internacional e o gerenciamento de contas públicas de I\&D através da centralização do planejamento e do orçamento de todas as despesas públicas em ciência e tecnologia(Laranja 2012, p. 660).

Revista Brasileira de Políticas Públicas e Internacionais, v.3, n.2, Dezembro/2018, pp. 29-58. 
NIWA, Tiago Hideki. Exercício de análises de políticas públicas: o Programa Estratégico para o Empreendedorismo e Inovação do Governo de Portugal (Programa +e+i).

Figura 1 - Innovation policies in Portugal. First stage, late 1960s to mid-1980s (reference date 1985)

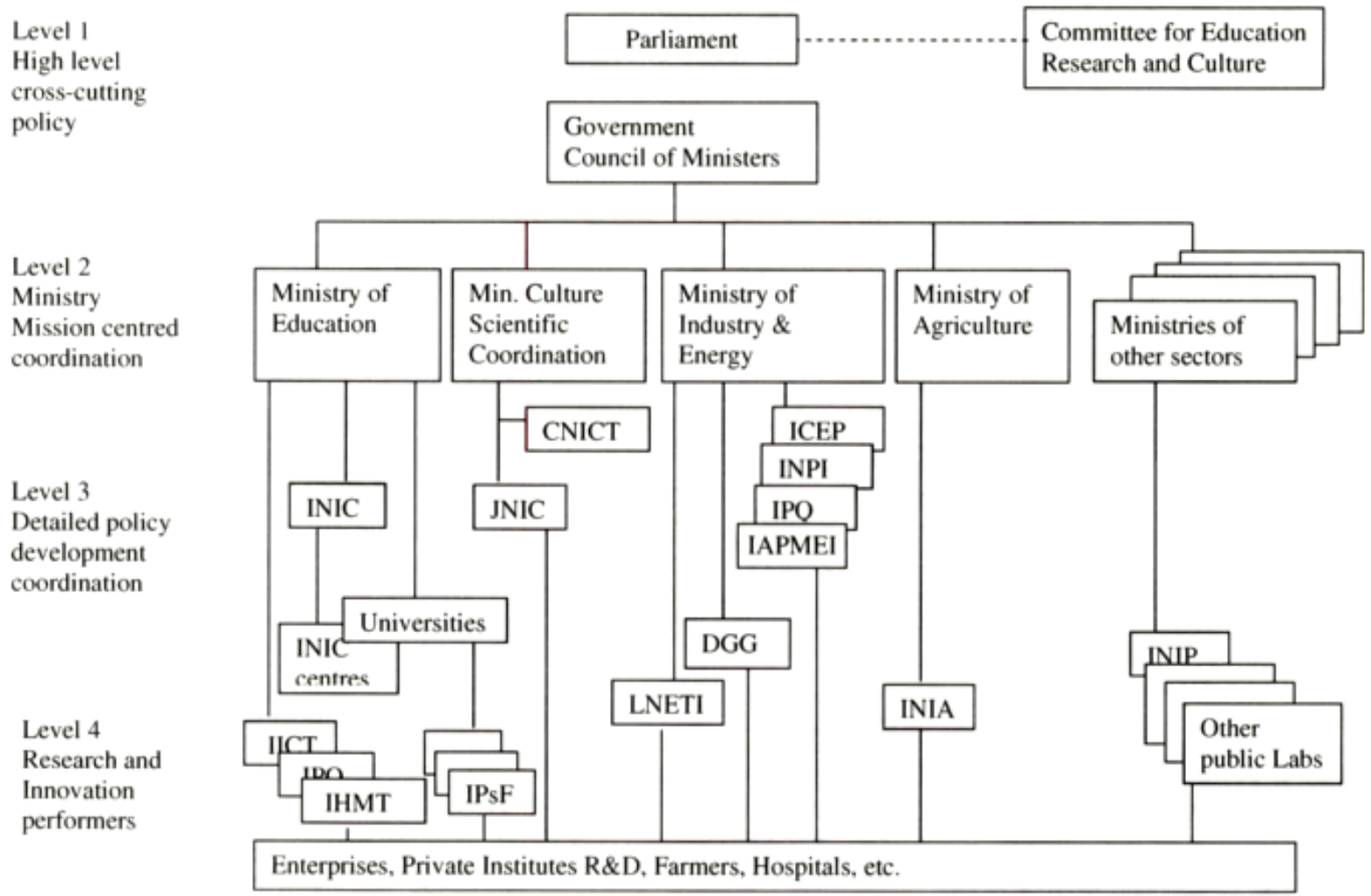

Fonte: Laranja, 2012, p. 660.

Reconhecendo que as políticas de I\&D tiveram diferentes direções, os governos portugueses, do final de 1970 e início de 1980, decidiram criar (que muitas vezes era a reestruturação ou renomeação de estruturas já existentes) os chamados Laboratórios do Estado. Tratam-se de organizações públicas de investigação ligados a diferentes ministérios e organizados por diferentes setores, tais como a agricultura, a pesca, a indústria, a construção, a saúde, ou por domínios científicos e tecnológicos, tais como geofísica, geologia e hidrografia (Laranja 2012, p. 660).

No final de 1970, o setor de ensino superior em Portugal procurava definir a sua própria política e programas de investigação autônomas. Nessa época, centros de pesquisa em universidades dependiam de uma hierarquia dupla. Portanto, a primeira fase pode, portanto, ser

Revista Brasileira de Políticas Públicas e Internacionais, v.3, n.2, Dezembro/2018, pp. 29-58. 
NIWA, Tiago Hideki. Exercício de análises de políticas públicas: o Programa Estratégico para o Empreendedorismo e Inovação do Governo de Portugal (Programa +e+i).

caracterizada por problemas de legitimidade da JNICT; pela criação de uma estrutura pública dualista e vertical de I\&D; pela ausência de uma visão compartilhada para o planejamento de longo prazo, e; pouca ou nenhuma atenção dada à inovação nas empresas. (Laranja 2012, p. 660).

Ainda, os acontecimentos da Revolução de 1974, em Portugal, e a consolidação da democracia e da integração europeia, iriam acentuar a necessidade de uma reformulação do modelo paradigmático do desenvolvimento econômico. Portanto, foi um contexto propício para se reforçar ideias para a interação entre a Ciência e a Tecnologia, e o desenvolvimento econômico, consubstanciando a nova teoria do crescimento econômico durante os anos 1980. A nova teoria econômica seria, portanto, propor, à imagem do modelo japonês, a promoção de relações estreitas entre os setores econômicos, industriais, da ciência e das políticas de investigação tecnológica (Brandão 2015, p. 4).

A segunda fase tem início no final de 1980 (Figura 2), logo após Portugal aderir à UE. O acesso a fundos comunitários estruturais (FE) e dos Fundos de Coesão da UE (CFS) contribuiu para fragmentar ainda mais a estrutura institucional quanto à política de inovação. A principal preocupação era em prestar apoio às pequenas e médias empresas (PME), através do desenvolvimento de infra-estruturas tecnológicas, tais como centros orientados para o setor de tecnologia (CTS), ou centros de transferência de tecnologia (CTT) e institutos de novas tecnologias (INTs). Em meados de 1990, os esforços do Ministério da Economia, combinados com a criação do Ministério da Ciência e Tecnologia, originou uma bipolarização ainda mais forte entre política de investigação e de inovação. Além disso, desde o final dos anos 1980, o acessoà UEe aos fundos estruturais (FE) trouxe o desenvolvimento de uma nova abordagem para a governança em vários níveis(Laranja 2012, p. 661).

Figura 2 - Innovation policies in Portugal. Second stage, late 1980s to 2000 (reference date 1997). Creation of the Ministry of S\&T

Revista Brasileira de Políticas Públicas e Internacionais, v.3, n.2, Dezembro/2018, pp. 29-58. 
NIWA, Tiago Hideki. Exercício de análises de políticas públicas: o Programa Estratégico para o Empreendedorismo e Inovação do Governo de Portugal (Programa +e+i).

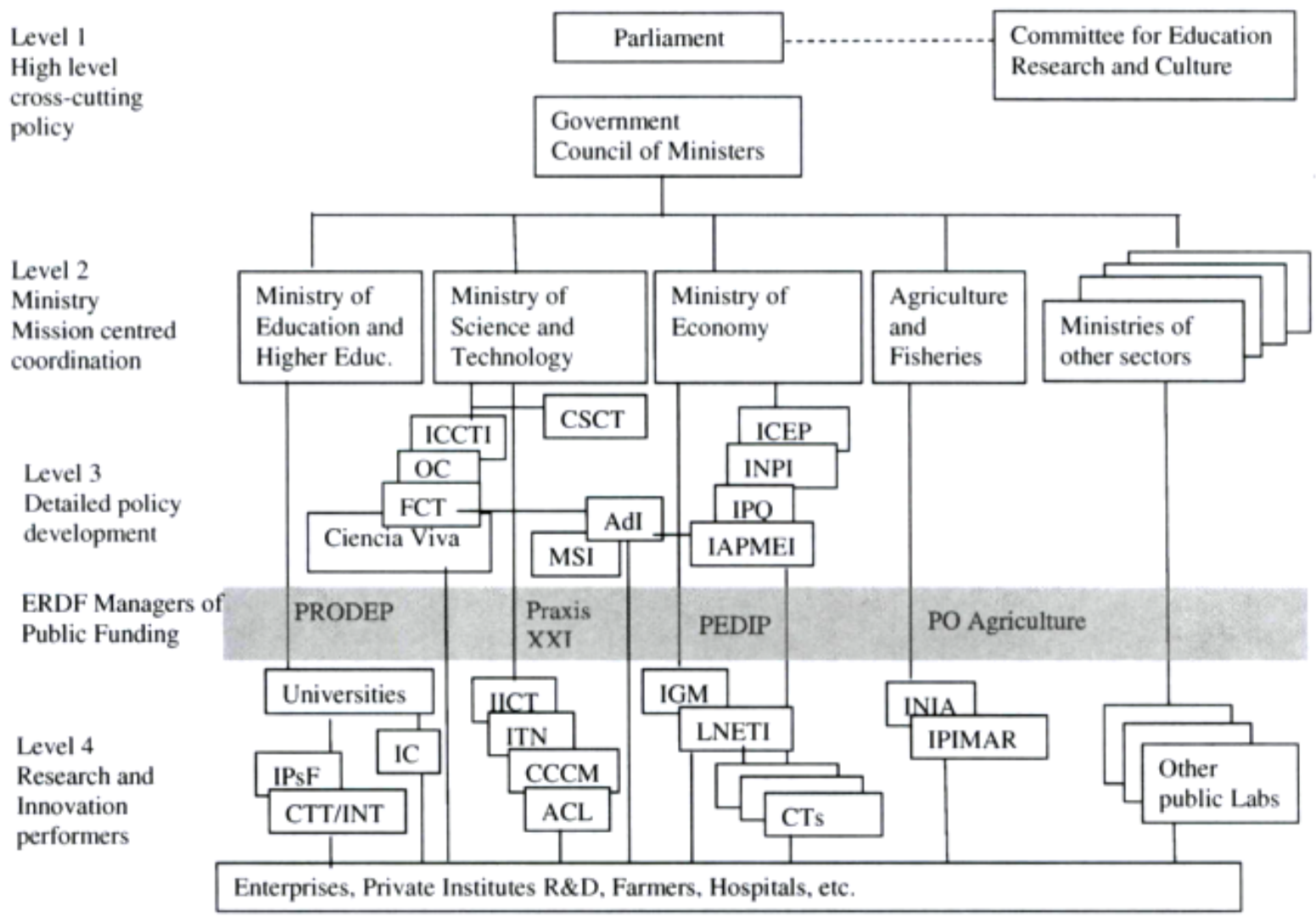

Fonte: Laranja, 2012, p. 661.

No final de 1980 e início de 1990, houve a utilização de fundos estruturais da União Europeia para financiar uma estratégia de recuperação rápida do atraso, focando-se na construção de infraestruturas públicas e bipolarizadas em torno de políticas de ciência, e de transferência de tecnologia e inovação, até o final da década de 1990. Assim, devido à diversidade institucional mais ampla e níveis mais elevados de recursos, fez-se mais sentido emergir políticas integradas e sistêmicas de nova abordagem de governança(Laranja 2012, p. 662).

Por isso, os governos preocupados com o crescimento econômico desencadearam uma série de políticas para apoiar o investimento da ciência e do conhecimento, bem como aumentar a cooperação entre as universidades e laboratórios do Estado com as empresas, visando o desenvolvimento tecnológico. Os governos de Portugal têm incentivado a criação de parques científicos e tecnológicos e incubadoras de empresas como infraestruturas fundamentais para a

Revista Brasileira de Políticas Públicas e Internacionais, v.3, n.2, Dezembro/2018, pp. 29-58. 
NIWA, Tiago Hideki. Exercício de análises de políticas públicas: o Programa Estratégico para o Empreendedorismo e Inovação do Governo de Portugal (Programa +e+i).

criação de habitats por excelência para o incentivo ao empreendedorismo e à cooperação com universidades(Marques et al. 2006, p. 538).

Na transição para a década de 1990,a OCDE intensificava sua interpretação sobre as tendências políticas destinadas a melhorar o envolvimento da inovação no setor privado, especialmente por meio de incentivos fiscais, de melhoria do acesso aos resultados de I\&D e tecnologias desenvolvidas em universidades e laboratórios públicos, com o apoio de regulamentações, e, também, a liberalização das leis de defesa da concorrência para facilitar o estabelecimento de consórcios de I\&D entre empresas(Brandão 2015, p. 4).

Durante grande parte da década de 1990, o crescimento econômico em Portugal era superior à média da União Europeia (UE), mas a partir da década de 2000 levou a uma situação desfavorável, recebendo apoio do Fundo Monetário Internacional (FMI) e do Fundo Europeu de Estabilização Financeira, passando por drásticos cortes orçamentários(Kauko \& Diogo 2011, p. 117).

Em relação à terceira fase, destacam-se os sinais de mudança no documento de referência estratégico nacional, nomeando os fundos estruturais para o período de 2000 a 2006 (Figura 3). Neste documento, a inovação aparece, pela primeira vez, como política de prioridade nacional dentro de um enquadramento econômico, científico e de outras políticas setoriais. Em 2001, a iniciativa Proinov, conduzida centralmente pela Presidência do Conselho de Ministros, foi uma tentativa de superar um esquema de governança transversal através de um conjunto mais amplo de áreas políticas, abarcando a ciência, a educação, a sociedade da informação e a inovação(Laranja 2012, p. 662).

Figura 3 - Innovation policies in Portugal. Third stage 2001-4 (reference date 2002). Innovation as an umbrella policy

Revista Brasileira de Políticas Públicas e Internacionais, v.3, n.2, Dezembro/2018, pp. 29-58. 
NIWA, Tiago Hideki. Exercício de análises de políticas públicas: o Programa Estratégico para o Empreendedorismo e Inovação do Governo de Portugal (Programa +e+i).

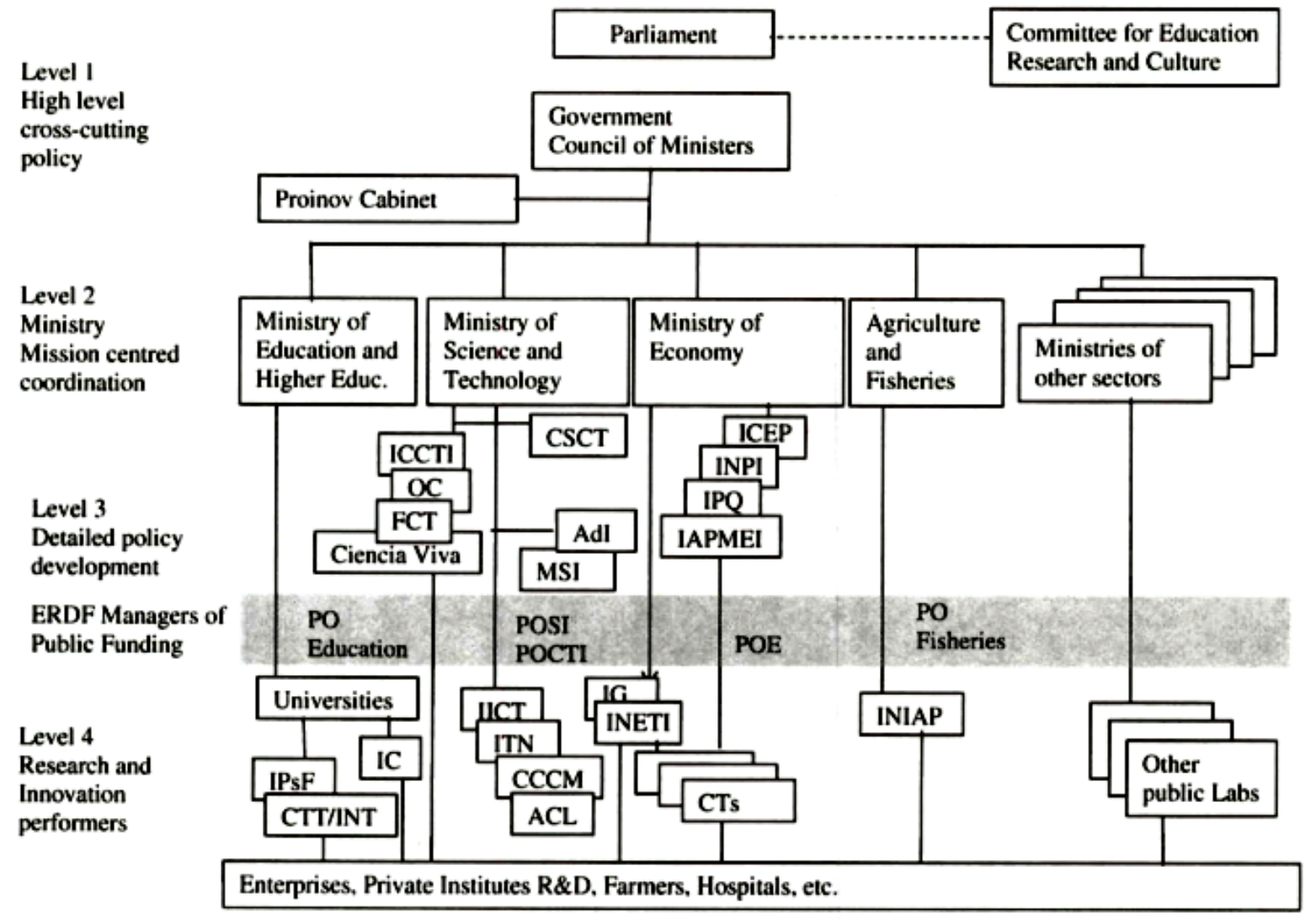

Fonte: Laranja, 2012, p. 662.

Todavia, com o advento de um novo governo em 2002, o Proinov encerrou suas atividades pouco depois de seu lançamento, sem ter tido tempo suficiente para demonstrar os potenciais benefícios de uma nova governança horizontal. Pode-se dizer que, nesta fase, a política de inovação em Portugal começou a ser compreendido como uma política guarda-chuva para outras políticas setoriais (Laranja 2012, p. 662).

Salienta-se que, em 2006, e a pedido do governo português, a OCDE e a Rede Europeia para a Garantia da Qualidade no Ensino Superior(ENQA) realizaram uma extensa revisão do sistema de ensino superior do país. O objetivo foi o de propor reformas e adotar as orientações

Revista Brasileira de Políticas Públicas e Internacionais, v.3, n.2, Dezembro/2018, pp. 29-58. 
NIWA, Tiago Hideki. Exercício de análises de políticas públicas: o Programa Estratégico para o Empreendedorismo e Inovação do Governo de Portugal (Programa +e+i).

europeias, que foram aprovadas no âmbito do processo de Bolonha (Kauko \& Diogo 2011, p. 121).

Verifica-se que o desenvolvimento das políticas de inovação, enquanto efeitos colaterais do próprio Plano Tecnológico, desencadeou em um aumento nas reivindicações setoriais para uma maior participação no processo global de concepção da política de inovação, colocando desafios ainda maiores para o futuro da governança dessas políticas (Laranja 2012, p. 666).

Em março de 2007, a Fundação para a Ciência e Tecnologia (FCT), de Portugal, lançou a University Technology Enterprise Network (Uten), conjuntamente com o Instituto IC2, da Universidade do Texas em Austin. Este programa plurianual representa um investimento significativo na inovação pelo Governo Português com um objetivo específico de construção de uma ciência e tecnologia globalmente competitivo e sustentável (C\&T)(Gibson \& Naquin 2011, p. 1304-1305).

A Uten procura aumentar a base de conhecimento dentro de Portugal com o fim de melhorar a competitividade de sua economia em escala global. Para tanto, este programa visa realizar a transferência de conhecimento e de tecnologia para agentes portugueses, bem como construir parcerias e redes sustentáveis entre especialistas e centros de inovação tecnológica em Portugal com o fim de fortalecer relações entre a ciência e a indústria, a gestão da inovação, a transferência de tecnologia, e de oportunidades para o empreendedorismo português, entre outros(Gibson \& Naquin 2011, p. 1304-1305).

Assim, acredita-se que o agendamento da medida de política pública em inovação, em Portugal, possui uma trajetória de conformidade às teorias econômicas internacionais vigentes, cujas etapas subsequentes da política específica em análise serão a seguir apresentadas.

\section{O empreendedorismo e a inovação como prioridades da formulação da política}

Revista Brasileira de Políticas Públicas e Internacionais, v.3, n.2, Dezembro/2018, pp. 29-58. 
NIWA, Tiago Hideki. Exercício de análises de políticas públicas: o Programa Estratégico para o Empreendedorismo e Inovação do Governo de Portugal (Programa +e+i).

A etapa de formulação de uma política pública consubstancia-se no desenvolvimento de propostas e soluções a fim de auxiliar a resolver uma demanda pública (Kraft \& Furlong 2009, p. 80).

A formulação da medida de política pública em análise está circunscrita na realidade das atuais economias em incentivar a inovação para com o empreendedorismo e à indústria, enquanto importante característica para aumentar a competitividade e melhorar a economia nacional. O Programa +e+i é um Programa do XIX Governo Constitucional de Portugal, que aponta o empreendedorismo e a inovação como objetivos prioritários para o desenvolvimento e para o aumento da competitividade da economia nacional(Portugal, 2015).

As prioridades da estratégia Europa2020 e da sua iniciativa Innovation Union são referenciais para o desenvolvimento da política de inovação em Portugal para os próximos anos. Além das tradicionais entidades e redes de coordenação criadas ao nível executivo, criou-se um órgão consultivo ao mais alto nível (junto do Primeiro-Ministro), denominado CNEI - Conselho Nacional para o Empreendedorismo e a Inovação, para que pudesse contribuir para uma orientação estratégica das políticas de inovação, maior coerência do sistema nacional de inovação e uma eficaz implementação do Programa +e+i (DRRCM35, 2011; Resolução do Conselho de Ministros n. ${ }^{\circ}$ 54, de 16 de dezembro de 2011, 2011).

A medida da política foi oficializada pela Resolução do Conselho de Ministros n. ${ }^{\circ}$ 54/2011, publicada no Diário da República em 16 de dezembro de 2011, em que designa ao Ministro da Economia e do Emprego a implementação do Programa +e+i, por delegação do Primeiro Ministro Pedro Passos Coelho (DRRCM35, 2011; Resolução do Conselho de Ministros n. ${ }^{\circ}$ 54, de 16 de dezembro de 2011, 2011).

Antecipadamente à exposição da concretização da medida de política, demonstram-se, na Tabela 1, as descrições das iniciativas e ações do Programa +e+i, do Governo de Portugal, enquanto fronteiras simbióticas entre a formulação e a concretização da medida.

Tabela 1 - O autor, de acordo com as informações do web site oficial do "Programa $+e+i$ "

Revista Brasileira de Políticas Públicas e Internacionais, v.3, n.2, Dezembro/2018, pp. 29-58. 
NIWA, Tiago Hideki. Exercício de análises de políticas públicas: o Programa Estratégico para o Empreendedorismo e Inovação do Governo de Portugal (Programa +e+i).

\begin{tabular}{|c|c|}
\hline $\begin{array}{l}\text { INICIATIVAS DO } \\
\text { PROGRAMA +E+I }\end{array}$ & DESCRIÇÃO \\
\hline $\begin{array}{l}\text { Passaporte para } 0 \\
\text { Empreendedorismo }\end{array}$ & $\begin{array}{l}\text { Definição: } \\
\text { A iniciativa pretende estimular jovens empreendedores } \\
\text { qualificados a desenvolverem o seu projeto de } \\
\text { empreendedorismo inovador, que se encontre em fase de } \\
\text { ideia, facultando um conjunto de ferramentas técnicas e } \\
\text { financeiras. } \\
\text { Objetivos e aplicabilidade: } \\
\text { a) Bolsa do Passaporte para o Empreendedorismo: o processo } \\
\text { inicia-se através do acesso a uma Bolsa para o } \\
\text { desenvolvimento do projeto empresarial; } \\
\text { b) Mentoria: os promotores com Bolsa podem ter acesso a } \\
\text { uma Rede Nacional de Mentores que irão fornecer } \\
\text { aconselhamento empresarial aos empreendedores; } \\
\text { c) Assistência Técnica: os promotores com Bolsa podem } \\
\text { ainda obter Assistência Técnica no desenvolvimento do } \\
\text { projeto empresarial. }\end{array}$ \\
\hline $\begin{array}{l}\text { Rede Nacional de } \\
\text { Mentores }\end{array}$ & $\begin{array}{l}\text { Definição: } \\
\text { O Rede é gerida pelo IAPMEI, que busca estimular a ligação } \\
\text { entre profissionais experientes e de reconhecido mérito e } \\
\text { empreendedores que estejam a desenvolver as suas ideias de } \\
\text { negócio e projetos empresariais. Por isso, procura-se } \\
\text { encorajar a partilha de experiências e competências, contando } \\
\text { com o envolvimento da sociedade civil, para antecipar } \\
\text { problemas e procurar soluções. O apoio de profissionais com } \\
\text { experiência pode ajudar a diminuir as dificuldades iniciais } \\
\text { sentidas pelos empreendedores, tais como: } \\
\text { a) falta de definição da ideia de negócio; } \\
\text { b) falta de experiência na gestão de negócios ou de } \\
\text { conhecimentos sobre a cultura empresarial da região ou setor } \\
\text { e consequentes dificuldades de entrada no mercado; } \\
\text { c) falta de contatos com potenciais clientes; } \\
\text { d) dificuldades em se estabelecerem no mercado. }\end{array}$ \\
\hline
\end{tabular}

Objetivos e aplicabilidade:

Revista Brasileira de Políticas Públicas e Internacionais, v.3, n.2, Dezembro/2018, pp. 29-58. 
NIWA, Tiago Hideki. Exercício de análises de políticas públicas: o Programa Estratégico para o Empreendedorismo e Inovação do Governo de Portugal (Programa +e+i).

\begin{tabular}{|l}
\hline A RNM propõe o estabelecimento de ligações entre pessoas, \\
mas não define um programa específico de mentoria. O \\
mentor e o empreendedor ajustam a sua forma de atuação \\
dentro dos Princípios Orientadores que regem a RNM. O \\
empreendedor deve entrar em contato com os mentores \\
listados, "vender” o seu projeto, persuadindo um mentor a \\
aceitá-lo para mentoria. O Mentor e o empreendedor devem \\
indicar, no portal, que estabeleceram a relação de mentoria.
\end{tabular}

\section{Programa de Ignição $\quad$ Definição:}

O Programa de Ignição da Portugal Ventures possibilita o acesso a investimento de capital de risco de projetos inovadores de base científica e tecnológica em fase Seed. Em colaboração com a sua rede de parceiros (Ignition Partners Network), a Portugal Ventures pretende investir cerca de 20 milhões de euros por ano em projetos de iniciativa de empreendedores, orientados a produto, baseados em I\&D referenciado internacionalmente, inovadores e únicos, posicionados em cadeias de valores globais, implementáveis com recursos disponíveis, com tecnologia apropriável e um significativo potencial de mercado global. Os setores de investimento privilegiados são os de Tecnologias de Informação e de Comunicação, Eletrônica \& WEB, Ciências da Vida e Recursos Endógenos, Nanotecnologia e Materiais.

\section{Objetivos e aplicabilidade:}

O objetivo é fortalecer o ecossistema Português de empreendedorismo de base tecnológica e promover o desenvolvimento de uma economia moderna, mais competitiva e aberta para o mundo, com base em conhecimento, inovação e capital humano altamente qualificado, com um forte espírito empreendedor.

Os projetos selecionados pela Portugal Ventures beneficiarão de um investimento entre 100 a 750 mil euros, num máximo de $85 \%$ do orçamento do projeto.

As candidaturas à Call podem ser apresentadas diretamente pelos empreendedores ou através dos parceiros da Ignition Partners Network: Anje, Beta-i, Biocant, CEIM/U. Madeira, Cotec, DNA Cascais, Fábrica de StartUps, IPN, Iscte, Net, Parkurbis, StartUp Lisboa, Teclabs, Universidade de Aveiro,

Revista Brasileira de Políticas Públicas e Internacionais, v.3, n.2, Dezembro/2018, pp. 29-58. 
NIWA, Tiago Hideki. Exercício de análises de políticas públicas: o Programa Estratégico para o Empreendedorismo e Inovação do Governo de Portugal (Programa +e+i).

\begin{tabular}{|c|c|}
\hline & $\begin{array}{l}\text { Universidade do Algarve, Universidade de Évora, } \\
\text { Universidade do Minho e Universidade do Porto. }\end{array}$ \\
\hline $\begin{array}{l}\text { Agenda } \\
\text { Digital }\end{array}$ & $\begin{array}{l}\text { Definição: } \\
\text { Através da Resolução do Conselho de Ministros n. } \\
\text { 112/2012, de } 31 \text { de dezembro, o Governo aprovou a Agenda } \\
\text { Portugal Digital, promovendo o seu alinhamento com os } \\
\text { objetivos definidos para o reforço da competitividade e da } \\
\text { internacionalização das empresas nacionais, em especial das } \\
\text { pequenas e médias empresas, através da inovação e do } \\
\text { empreendedorismo qualificado. }\end{array}$ \\
\hline
\end{tabular}

\section{Objetivos e aplicabilidade:}

Os objetivos da Agenda Portugal Digital são os listados a seguir:

a) Promover o desenvolvimento da infraestrutura de banda larga, de forma a permitir que todos os cidadãos possam ter acesso à banda larga de velocidade igual ou superior a 30 Mbps, até 2020;

b) Promover o desenvolvimento da infraestrutura de banda larga, de forma a permitir que $50 \%$ dos agregados familiares possam ter acesso à Internet de banda larga de velocidade igual ou superior a 100 Mbps, até 2020;

c) Criar as condições que permitam o aumento em $55 \%$, face aos valores de 2011, do número de empresas que utilizam o comércio eletrônico em Portugal, até 2020;

d) Promover junto da população portuguesa uma maior utilização dos serviços públicos online, convergindo, até 2020, com a média europeia;

e) Criar as condições que permitam o aumento em $25 \%$ das exportações em Tecnologias de Informação e Comunicação (TIC), em valores acumulados, até 2020, tendo como referência o ano de 2011;

f) Promover a utilização das novas tecnologias, para que seja possível diminuir para 23\% o número de pessoas que nunca utilizou a Internet, até 2020;

g) Promover a Inovação em TIC e reforçar o potencial em I\&D contando com o aumento do financiamento público

Revista Brasileira de Políticas Públicas e Internacionais, v.3, n.2, Dezembro/2018, pp. 29-58. 
NIWA, Tiago Hideki. Exercício de análises de políticas públicas: o Programa Estratégico para o Empreendedorismo e Inovação do Governo de Portugal (Programa +e+i).

\begin{tabular}{l|l}
\hline & $\begin{array}{l}\text { direto à I\&D em TIC em 10\% até 2020, tendo como } \\
\text { referência os dados de } 2012 .\end{array}$ \\
\hline PME Digital & Definição: \\
& A PME digital é uma iniciativa do Ministério da Economia, \\
& que pretende ajudar as micro e pequenas e médias empresas \\
& portuguesas a serem mais competitivas. Ao estimular a \\
& utilização de ferramentas digitais, permite o acesso a novos \\
& mercados, melhorar a gestão e tornar mais eficiente a relação
\end{tabular}
com os clientes e fornecedores.

\section{Objetivos e aplicabilidade:}

O objetivo desta iniciativa é aumentar o número de empresas na economia digital. Por meio de entidades e parceiros, a PME Digital auxilia na implementação dos seguintes pacotes de serviços nos empreendimentos:

a) O Pacote PRESENÇA ONLINE inclui contas de correio profissionais e o site institucional, com endereço personalizável, que permite a apresentação da empresa, a promoção dos seus produtos e serviços bem como informação de contato. Este pacote inclui ainda formação base sobre a utilização de cada um dos componentes da solução bem como o suporte à implementação inicial e à atualização futura do site;

b) O Pacote LOJA ONLINE inclui contas de correio profissionais, site com endereço personalizável e loja online, que permite a venda de produtos e serviços. Inclui carrinho de compras, logística, pagamentos e ferramentas de vendas e marketing. Este pacote inclui, ainda, formação base sobre a utilização de cada um dos componentes da solução bem como o suporte à implementação inicial e à atualização futura do site;

c) Os Pagamentos Eletrônicos são um conjunto de serviços que permitem facilitar, agilizar e encurtar os processos de pagamento dos seus clientes. Inclui soluções de pagamento para lojas online, para pagamento de faturas, mensalidades, quotas ou mesmo angariação de donativos. Os serviços incluem o acompanhamento e formação na utilização dos Pagamentos Eletrônicos em cada situação especifica;

d) O Pacote PRODUTIVIDADE inclui um conjunto de aplicações que permite criar, editar, guardar e partilhar documentos (i.e. Texto, Folhas de Cálculo, Gráficos,

Revista Brasileira de Políticas Públicas e Internacionais, v.3, n.2, Dezembro/2018, pp. 29-58. 
NIWA, Tiago Hideki. Exercício de análises de políticas públicas: o Programa Estratégico para o Empreendedorismo e Inovação do Governo de Portugal (Programa +e+i).

Imagens, Apresentações, etc.). Estas soluções podem ainda incluir funcionalidades de Chamadas PC-PC e vídeo conferências com diversos interlocutores;

e) O Serviço ACESSO inclui a ligação à internet em banda larga (fixa ou móvel) e, em algumas opções, o serviço de voz e também o computador (Fixo, Portátil, Tablet). Destina-se a quem ainda não tem meios de acesso à Internet. Este pacote inclui também o equipamento e a instalação necessárias para o acesso à internet;

f) O serviço de Integração em Plataformas Eletrônicas de Compra e Venda permitem negócios entre empresas de todo o mundo (B2B) e ao Estado Português (B2G). Inclui a integração do negócio e do catálogo de produtos em plataformas profissionais. Também pode incluir a plataforma de compras para poder fazer o aprovisionamento de produtos e serviços de outras empresas;

g) O serviço ERP (Enterprise Resource Planning) é um sistema informático de gestão empresarial que integra todas as funções mais importantes da empresa. Inclui, por exemplo, a gestão de Clientes e Vendas, Produtos e Stocks, Vendedores, Fornecedores e Compras, Tesouraria, Documentos/Relatórios. Todas as soluções apresentadas são certificadas e permitem a emissão do ficheiro SAF-T PT para as Finanças;

h) O serviço CRM (Customer Relationship Management) é um sistema informático de gestão dos clientes que reúne vários processos de uma forma organizada e integrada. As soluções de CRM incluem módulos de gestão de Campanhas/Negócios, "Leads"/clientes potenciais, Atividades/Marcações, Newsletters/Outras Ferramentas de Comunicação e ainda Documentos / Relatórios. Incluem, normalmente, uma integração com um ou mais ERP e muitas outras funcionalidades;

i) A Faturação Eletrônica é uma solução para as empresas que pretendam simplificar os seus processos, aumentar a eficiência e reduzir os custos administrativos e erros. Tratase de uma solução na qual existem documentos com campos informativos pré-definidos para cada tipo de operação comercial, desde o pedido de encomenda, passando pela guia de remessa, até à emissão das faturas;

j) Depois de criada a sua loja online, encontre o parceiro que lhe garante serviços integrados de recolha, armazenagem e distribuição dos seus produtos na morada pretendida de forma

Revista Brasileira de Políticas Públicas e Internacionais, v.3, n.2, Dezembro/2018, pp. 29-58. 
NIWA, Tiago Hideki. Exercício de análises de políticas públicas: o Programa Estratégico para o Empreendedorismo e Inovação do Governo de Portugal (Programa +e+i).

\begin{tabular}{l|l}
\hline rápida, segura e eficiente. A pensar no serviço de entrega \\
especialmente destinado ao e-commerce, apresentamos as \\
melhores soluções de entrega que garantem rapidez, \\
informação e soluções alternativas que permitam uma maior \\
liberdade e autonomia, proporcionando às PMEs uma \\
fidelização dos seus clientes; \\
k) O Serviço de Certificação de Site e Lojas Online inclui a \\
avaliação da conformidade do site/loja online segundo a \\
legislação portuguesa e as melhores práticas europeias. A \\
certificação é fundamental para os comerciantes online \\
porque promove as boas-práticas e a qualidade dos processos, \\
mas também porque aumenta a confiança dos consumidores \\
na loja online da empresa.
\end{tabular}

Guia Prático do

O Guia Prático do Empreendedor constitui uma ferramenta de trabalho para o empreendedor, sendo sistematizada a informação essencial para aqueles que têm uma ideia, deseja criar uma empresa ou expandir a sua atividade.

\section{Objetivos e aplicabilidade:}

Procura orientar os empreendedores para suas atividades nos seguintes aspectos:

a) Desenvolvimento da Ideia e do Plano de Negócios

b) Constituição da empresa e ligação a serviços do Estado

c) Apoio às empresas e instrumentos de financiamento

d) Links para plataformas online e estruturas locais.

\begin{tabular}{l|l}
\hline Selo +e+i & Definição: \\
& O Programa Estratégico para o Empreendedorismo e a \\
& Inovação $(+\mathrm{e}+\mathrm{i})$ concede o apoio institucional, através da \\
& atribuição do "Selo +e+i”, às iniciativas desenvolvidas por \\
empresas, entidades de I\&D, universidades, entidades \\
públicas e privadas, que se insiram no espírito do +e+i e que \\
contribuam para estimular a cultura e as práticas de \\
empreendedorismo e inovação. \\
A primeira iniciativa com este "selo" foi a Energia de \\
Portugal, organizada pela Fábrica de Startups e lançada pelo
\end{tabular}

Revista Brasileira de Políticas Públicas e Internacionais, v.3, n.2, Dezembro/2018, pp. 29-58. 
NIWA, Tiago Hideki. Exercício de análises de políticas públicas: o Programa Estratégico para o Empreendedorismo e Inovação do Governo de Portugal (Programa +e+i).

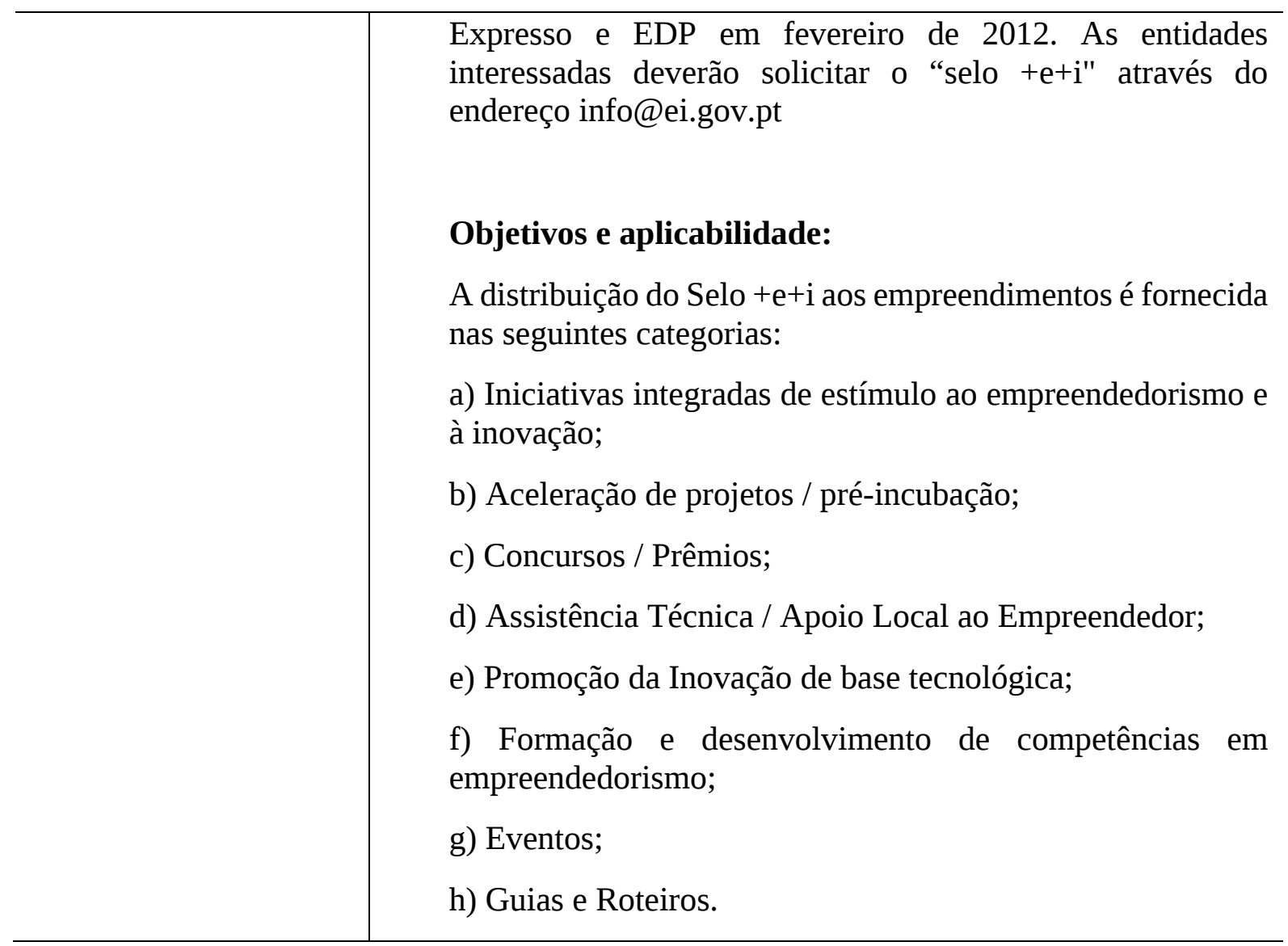

Fonte: Portugal, 2015.

\section{A concretização política do Programa +e+i}

No que tange à concretização da medida de política, averígua-se que se trata de uma etapa crucial quanto à análise do desenho de políticas públicas, haja vista que se trata do momento em que se compreende a concreta atuação governamental e as reais consequências para a sociedade (Kraft \& Furlong 2009, p. 84).

O Programa Estratégico para o Empreendedorismo e a Inovação - Programa +e+i, implementado pela Resolução do Conselho de Ministros n. ${ }^{\circ}$ 54/2011, e complementado pela Declaração de Retificação n. ${ }^{\circ}$ 35/2011, assenta-se em quatro pilares fundamentais, a saber (DRRCM35, 2011):

Revista Brasileira de Políticas Públicas e Internacionais, v.3, n.2, Dezembro/2018, pp. 29-58. 
NIWA, Tiago Hideki. Exercício de análises de políticas públicas: o Programa Estratégico para o Empreendedorismo e Inovação do Governo de Portugal (Programa +e+i).

(i) no alargamento das competências da população, incluindo a população jovem e a socialmente desprotegida, das empresas e da Administração Pública;

(ii) na dinamização da inovação, designadamente ao nível de produto, processos e tecnologia, por forma a promover a competitividade das empresas portuguesas;

(iii) no estímulo ao empreendedorismo, promovendo um contexto favorável ao surgimento de projetos empreendedores e ao seu sucesso;

(iv) e na promoção destes objetivos através de adequados instrumentos de financiamento, com uma repartição justa dos fundos disponíveis pelas iniciativas de excelência.

A análise da concretização da medida de política baseia-se, dentre outros exercícios analíticos, em dados estatísticos acerca dos investimentos realizados em Investigação e Desenvolvimento (I\&D), fato que revela o potencial inovador de diversos setores de produção. Contudo, assevera-se que, em se tratando de um Programa recente, cujos efeitos dos investimentos e dos incentivos realizados são, muitas vezes, de médio a longo prazos, faz-se importante destacar as limitações da análise. Nesse diapasão, salienta-se que os dados relacionados podem revelar, para fins analíticos, uma sustentação empírica e informacional também para a etapa da avaliação da medida de política.

Por essa maneira, a Tabela 2(dados atualizados até 2013) informa, em valores em milhões de Euros, que houve decréscimo em despesas em atividades de Investigação e Desenvolvimento em montantes totais e também em empresas.

Tabela 2 - Despesas em atividades de Investigação e Desenvolvimento (I\&D): total e do sector empresas (Euro - milhões)

Revista Brasileira de Políticas Públicas e Internacionais, v.3, n.2, Dezembro/2018, pp. 29-58. 
NIWA, Tiago Hideki. Exercício de análises de políticas públicas: o Programa Estratégico para o Empreendedorismo e Inovação do Governo de Portugal (Programa +e+i).

Sectores de execução

$\begin{array}{lll}\text { Anos } & \text { Total } & \text { Empresas } \\ \mathbf{2 0 0 8} & 2.585 .074,9 & 1.295 .099,0 \\ \mathbf{2 0 0 9} & 2.771 .599,7 & 1.311 .069,6 \\ \mathbf{2 0 1 0} & 2.757 .554,6 & 1.266 .296,1 \\ \mathbf{2 0 1 1} & 2.566 .449,9 & 1.216 .345,6 \\ \mathbf{2 0 1 2} & 2.320 .132,8 & 1.153 .332,2 \\ \mathbf{2 0 1 3} & \text { (R) } 2.258 .471,0 & 1.072 .908,7\end{array}$

Fonte: Fontes de Dados: DGEEC/MEC - Inquérito ao Potencial Científico e Tecnológico Nacional (IPCTN); (Pordata, 2016) (Última atualização: 2015-11-04).

Embora a medida de política pública analisada vise fomentar a inovação e o empreendedorismo, nota-se, pela Figura 4 (dados atualizados de 2005 a 2013), que houve redução das despesas em I\&D, em montante em euros, nos setores empresariais e em instituições privadas sem fins lucrativos. No entanto, houve aumento dos investimentos no Ensino Superior, equivalendo, aproximadamente, aos montantes destinados às empresas, o que pode revelar indícios de desenvolvimento da inovação.

Figura 4 - Despesas em atividades de I\&D: total e por sector de execução

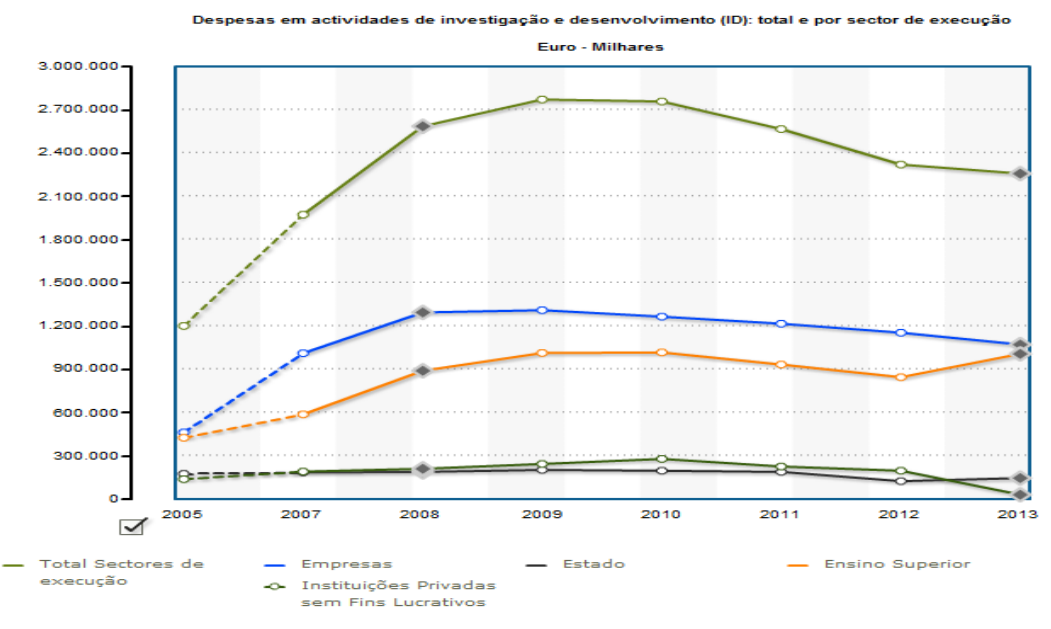

Revista Brasileira de Políticas Públicas e Internacionais, v.3, n.2, Dezembro/2018, pp. 29-58. 
NIWA, Tiago Hideki. Exercício de análises de políticas públicas: o Programa Estratégico para o Empreendedorismo e Inovação do Governo de Portugal (Programa +e+i).

Fonte: DGEEC/MEC - Inquérito ao Potencial Científico e Tecnológico Nacional (IPCTN); (Pordata, 2016)(Última actualização: 2015-11-03).

Embora as despesas em I\&D possam permitir inúmeras interpretações, e que suas variações possuem diversas causas não aparentes, acredita-se ser um indicador importante para medir a priorização governamental em desenvolver tecnologias e produzir inovações aos setores produtivos. Assim, a Figura 5 apresenta a constante queda das despesas em atividades de I\&D, em porcentagem do Produto Interno Bruto (PIB), tanto em valores totais dos setores de execução, quanto das empresas, a partir de 2009.

Figura 5 - Despesas em atividades de I\&D em \% do PIB

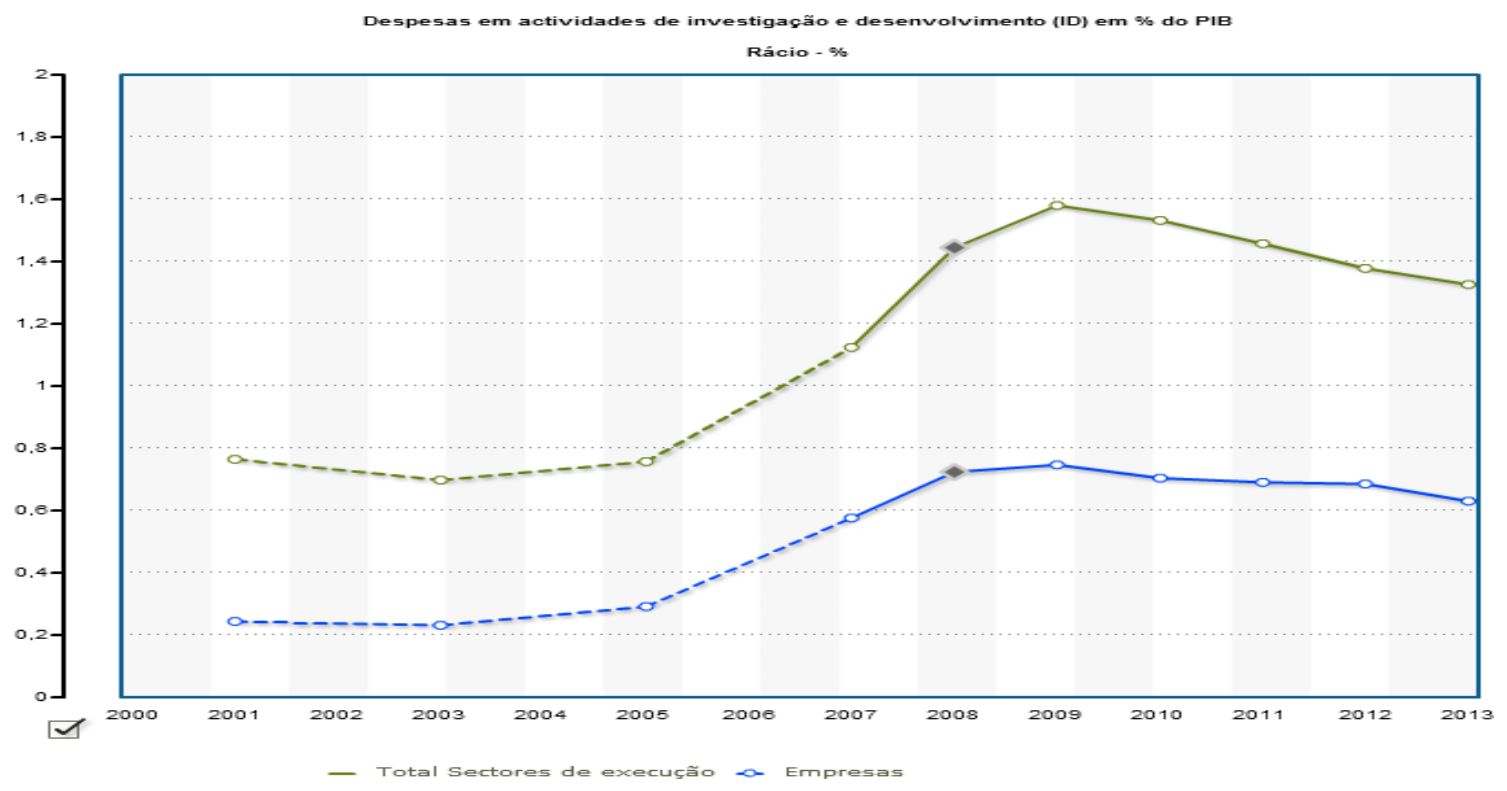

Fonte: INE | BP - Contas Nacionais Anuais (Base 2011)DGEEC/MEC - Inquérito ao Potencial Científico e Tecnológico Nacional (IPCTN); (Pordata, 2016)(Última actualização: 2015-11-04)

Um indicador que pode revelar a disponibilidade de recursos humanos para dedicação à I\&D é o número de investigadores em valores totais e em empresas, conforme se depreende da Figura 6. Em valores totais, verifica-se que houve um ápice de número de investigadores em atividades de I\&D em 2011, havendo posterior queda na quantidade disponível. Quanto aos Revista Brasileira de Políticas Públicas e Internacionais, v.3, n.2, Dezembro/2018, pp. 29-58. 
NIWA, Tiago Hideki. Exercício de análises de políticas públicas: o Programa Estratégico para o Empreendedorismo e Inovação do Governo de Portugal (Programa +e+i).

investigadores em empresas, verifica-se certa estabilidade, o que pode ser interpretado como a manutenção de empresas (ou mesmo sobrevivência dos mesmos) e de seus investigadores, em um contexto geral.

Figura 6 - Investigadores em atividades de I\&D, em valores totais e empresas

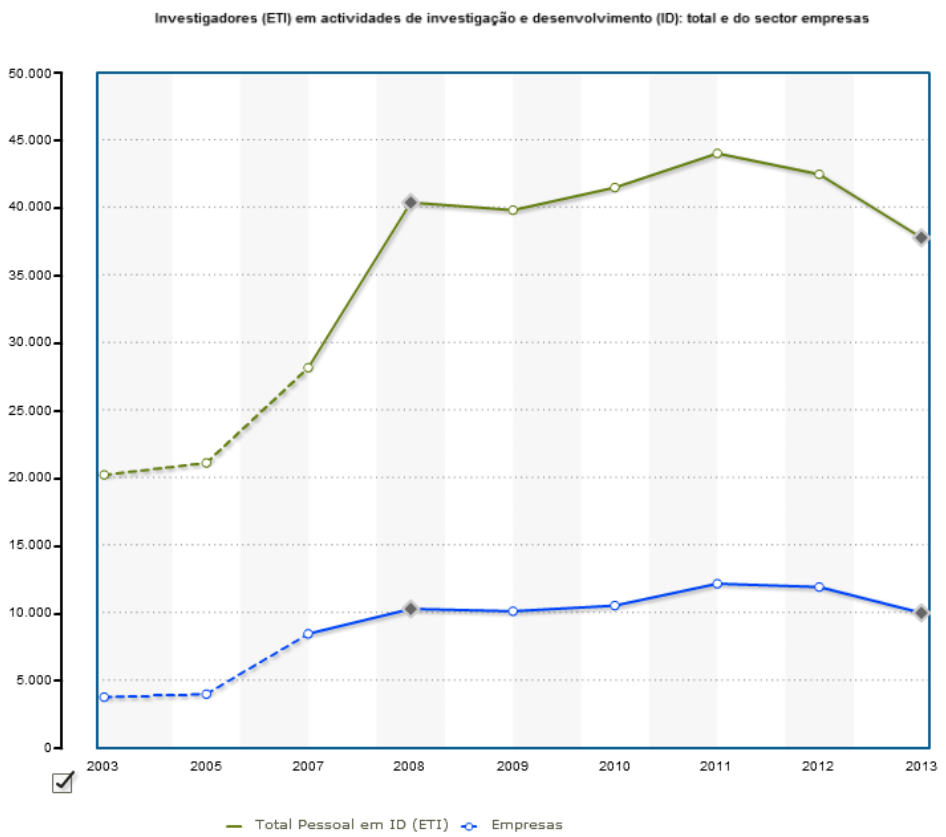

Fonte: DGEEC/MEC - Inquérito ao Potencial Científico e Tecnológico Nacional (IPCTN);(Pordata, 2016) (Última actualização: 2015-09-22).

Quando se analisa a quantidade total de pessoal em atividades de I\&D, por setores de execução, de acordo com a Figura 7, vislumbra-se que em números totais houve um grande aumento a partir de 2005 a 2008, havendo certa estabilidade nos anos subsequentes, com o ápice em 2011. Destaca-se o aumento, a partir de 2012, da quantidade de pessoal em atividades de I\&D no Ensino Superior, e a estabilidade na quantidade de pessoal em empresas de 2008 a 2013.

Revista Brasileira de Políticas Públicas e Internacionais, v.3, n.2, Dezembro/2018, pp. 29-58. 
NIWA, Tiago Hideki. Exercício de análises de políticas públicas: o Programa Estratégico para o Empreendedorismo e Inovação do Governo de Portugal (Programa +e+i).

Figura 7 - Quantidade de pessoal em I\&D, por sectores de execução

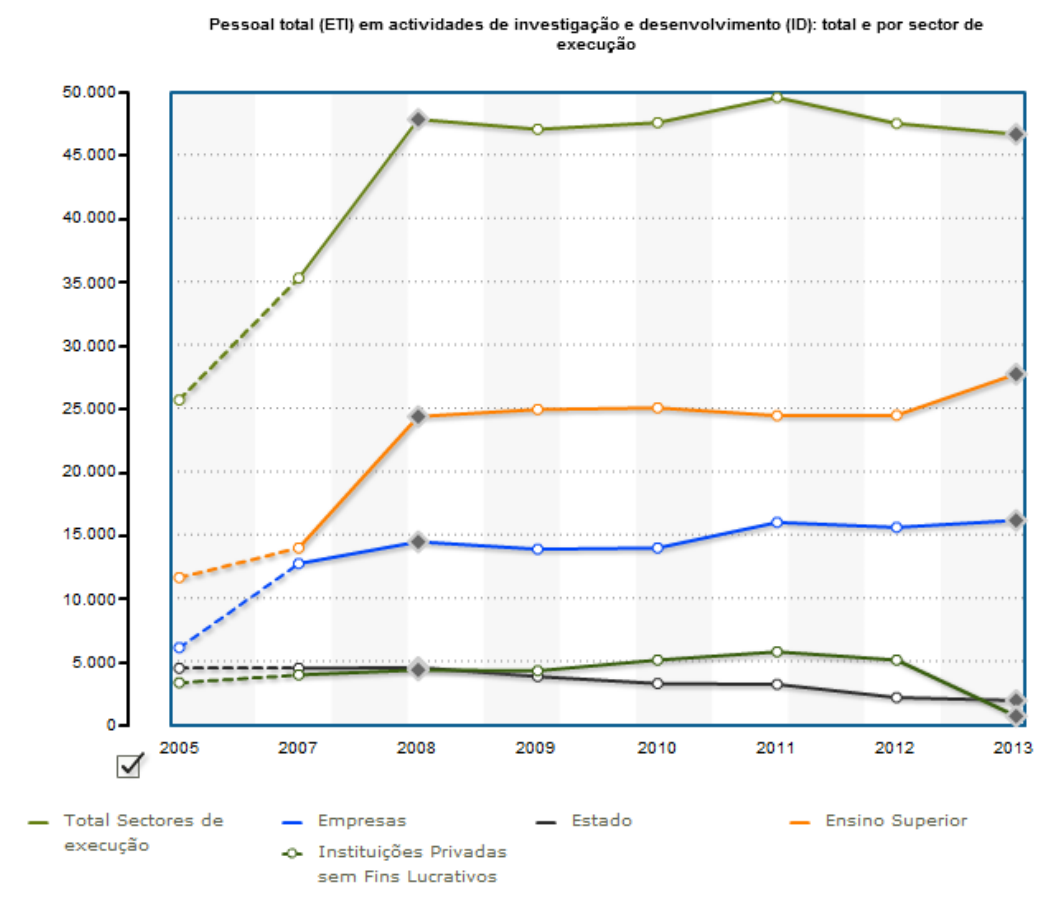

Fonte: DGEEC/MEC - Inquérito ao Potencial Científico e Tecnológico Nacional (IPCTN);(Pordata, 2016) (Última actualização: 2015-11-03).

Portanto, embora sejam multifatoriais as causas de aumento ou redução de investimentos em I\&D ou da quantidade de pessoal em I\&D, acredita-se como potenciais indicadores para demonstrar a concretização da medida de política, bem como alicerces para a sua avaliação.

Destaca-se, ainda, que o Programa +e+i apresenta o formato e a configuração já destacados pela literatura especializada, isto é, enquanto política pública que abarca outras ações setoriais (cada qual com suas peculiaridades). Assim, a concretização da medida de política foi realizada por meio de ato normativo do Conselho de Ministros, baseado em teorias econômicas vigentes.

O próximo capítulo destaca a avaliação da medida de política, muito embora os dados estatísticos apresentados possam também servir como fontes de estudos comparativos.

Revista Brasileira de Políticas Públicas e Internacionais, v.3, n.2, Dezembro/2018, pp. 29-58. 
NIWA, Tiago Hideki. Exercício de análises de políticas públicas: o Programa Estratégico para o Empreendedorismo e Inovação do Governo de Portugal (Programa +e+i).

\section{A avaliação da política em época de austeridade econômica em Portugal}

As etapas da avaliação e da mudança da medida de política são aquelas que demonstram se as políticas ou programas estão no rumo para o atingimento de seus objetivos e metas, e se houve mudanças necessárias para aumentar ou reduzir o escopo da medida, podendo iniciar um novo ciclo político, de acordo com as necessidades e realidades apresentadas (Kraft \& Furlong 2009, p. 85-87).

Para tanto, vislumbra-se acerca da influência de uma visão de políticas tecnológicas inseridas nos processos de políticas científicas, conciliando-as aos interesses de agentes econômicos nacionais e às necessidades de comunidades científicas. A transição das décadas de 1970 e 1980 preparou os parâmetros de políticas tecnológicas para a década de 1990, o que ocasionou um ciclo político de "imperativos tecnológicos" da política científica, sob a égide de culturas econômicas e burocráticas (Brandão 2015, p. 14-15).

Portugal, enquanto Estado-Membro da União Europeia (UE), ao aderir à Estratégia Europa 2020 e às medidas de austeridade inspirados pela tróica, estava, a princípio, no caminho de alcançar os objetivos propostos. No entanto, com o início da recessão econômica e social, a partir de 2007/2008, Portugal encontrou-se em um cenário de sérias dificuldades, tendo de se socorrer à UE. Essa situação obrigou o país a pagamentos de juros da dívida, cujo montante se mostrou maior do que o gasto público em educação, saúde e seguridade social em 2012/2013 (Lopes 2014, p. 56-57).

Ainda, considerando que o Governo Português não tenha solicitado qualquer tipo de reprogramação dos compromissos para o crescimento e emprego da Estratégia Europa 2020, as obrigações tornaram-se reféns das medidas de austeridade, que tiveram que ser implantadas para reduzir o déficit. Portanto, a inevitável descontinuidade das medidas políticas de incentivo e a redução nos investimentos em educação, I\&D e inovação, podem levar a um risco de dano irreversível para o crescimento e modernização do conhecimento (Lopes 2014, p. 56-57).

Portanto, embora a recessão econômica e social seja de magnitude internacional, atingindo investimentos ou dedicações à CT\&I, sabe-se, sobremaneira, que os esforços em

Revista Brasileira de Políticas Públicas e Internacionais, v.3, n.2, Dezembro/2018, pp. 29-58. 
NIWA, Tiago Hideki. Exercício de análises de políticas públicas: o Programa Estratégico para o Empreendedorismo e Inovação do Governo de Portugal (Programa +e+i).

investimentos em inovação são preocupações e realidades das economias mundiais, tendo em vista, em especial, as teorias econômicas vigentes. Nesse sentido, acredita-se que o agendamento e os debates públicos concernentes à inovação, principalmente pela cooperação entre a ciência e a indústria, são medidas permanentes e de longos prazos nas economias mundiais para o desenvolvimento econômico e social.

\section{Conclusão}

O tema deste estudo é uma discussão presente nas agendas políticas, tendo em vista se tratar de uma construção e desenvolvimento dos setores produtivos da economia. Outrossim, sabe-se que a impulsão da temática que relaciona a inovação ao empreendedorismo pode ser especialmente dirigível aos países em desenvolvimento, ou àqueles com suas economias fragilizadas, tendo em vista o potencial inovativo e o pretenso aumento da competitividade das suas economias nacionais, dentro de parâmetros sustentáveis de desenvolvimento.

No sentido de concluir o presente exercício de análise de política pública, acredita-se que o programa possui alguns pontos positivos e algumas fragilidades que podem ser levadas em consideração. Enquanto destaques positivos do Programa $+\mathrm{e}+\mathrm{i}$, observa-se que há a descrição dos objetivos de forma clara e interativa de suas iniciativas oficiais, o que facilita a adesão e o envolvimento dos atores relacionados à seara do empreendedorismo e da inovação. Um segundo ponto é que o cumprimento e os resultados do Programa +e+i são parcialmente publicados no sítio da internet, o que é importante para se avaliar a medida da política pública.

No que tange a eventuais fragilidades dessa política, destaca-se que a definição dos objetivos do Programa é genérica, necessitando de metas numericamente bem definidas para serem alcançadas. Um segundo ponto é que as informações dos resultados do Programa são parciais ou incompletas, carecendo da obrigatoriedade, pela própria Resolução, de apresentação de relatórios periódicos dos resultados, dos benefícios ou de eventuais necessidades de melhorias das iniciativas. E em terceiro e último ponto, acredita-se que tenha faltado uma iniciativa

Revista Brasileira de Políticas Públicas e Internacionais, v.3, n.2, Dezembro/2018, pp. 29-58. 
NIWA, Tiago Hideki. Exercício de análises de políticas públicas: o Programa Estratégico para o Empreendedorismo e Inovação do Governo de Portugal (Programa +e+i).

específica para a interação entre o empresariado e as Instituições de Ensino Superior de Portugal, especialmente para questões ligadas à inovação e à transferência de tecnologia.

Portanto, a concretização de políticas indutoras à inovação e ao empreendedorismo, especialmente no que concerne às pequenas e às médias empresas, necessita de acompanhamento e avaliação constantes para que haja a eventual reestruturação ou reconstrução das políticas públicas relacionadas.

\section{Referências}

Brandão, T. (2016). Shaping Portuguese science policy for the European horizon: The discourses of technological change. Technological Forecasting and Social Change, 113, 168-184. https://doi.org/10.1016/j.techfore.2015.09.014

Crispim, J., Braz, J., Castro, R., \& Esteves, J. (2014). Smart Grids in the EU with smart regulation: Experiences from the UK, Italy and Portugal. Utilities Policy, 31, 85-93. https://doi.org/10.1016/j.jup.2014.09.006

DRRCM35. (2011). Declaração de Rectificação n. ${ }^{\circ}$ 35/2011, de 21 de dezembro de 2011, referente à Resolução do Conselho de Ministros n. ${ }^{0}$ 54, de 16 de dezembro de 2011. Portugal: Diário da República, $1^{\text {a }}$ série, n. ${ }^{\circ}$ 243, p. 5.351.

Dye, T. R. (2011). Understanding Public Policy. (13th ed.). Boston: Longman.

Filion, L. J. (1999). Empreendedorismo: empreendedores e proprietários-gerentes de pequenos negócios. Revista de Administração, 34(2), 5-28.

Gibson, D. V., \& Naquin, H. (2011). Investing in innovation to enable global competitiveness:

The case of Portugal. Technological Forecasting and Social Change, 78(8), 1299-1309. https://doi.org/10.1016/j.techfore.2011.04.004.

Hill, M. (2013). The Public Policy Process. (6th ed.). New York: Routledge.

Revista Brasileira de Políticas Públicas e Internacionais, v.3, n.2, Dezembro/2018, pp. 29-58. 
NIWA, Tiago Hideki. Exercício de análises de políticas públicas: o Programa Estratégico para o Empreendedorismo e Inovação do Governo de Portugal (Programa +e+i).

Kauko, J., \& Diogo, S. (2011). Comparing higher education reforms in Finland and Portugal : different contexts, same solutions ? Comparaison des réformes de renseignement supérieur en Finlande et au Portugal : contextes différents , solutions identiques ?, 23.

Kingdon, J. W. (1995). Agendas, alternatives, and public policies. (2nd ed.). New York: Longman.

Kraft, M. E., \& Furlong, S. R. (2009). Public Policy: Politics, Analysis, and Alternatives.(3rd ed.). Washington: CQPress.

Lakatos, E. M., \& Marconi, M. de A. (2010). Fundamentos de Metodologia Científica (7th ed.). São Paulo: Atlas.

Laranja, M. (2012). Network governance of innovation policies: The Technological Plan in Portugal. Science and Public Policy, 39(5), 655-668. https://doi.org/10.1093/scipol/scs043

Lopes, M. M. S. C. (2014). The Development of Knowledge in Portugal: A Slow and Unsustainable Progress. IUP Journal of Knowledge Management, 12(3), 42-60.

Marques, J. P. C., Caraça, J. M. G., \& Diz, H. (2006). How can university-industry-government interactions change the innovation scenario in Portugal? - the case of the University of Coimbra. Technovation, 26(4), 534-542. https://doi.org/10.1016/j.technovation.2005.04.005

Pordata. (2016). Pordata: Banco de dados Portugal Contemporâneo. Retrieved April 30, 2016, from http://www.pordata.pt/

Portugal. (2015). Programa Estratégico para o Empreendedorismo e a Inovação (Programa +e+i). Retrieved November 1, 2015, from http://www.ei.gov.pt/index/

Resolução do Conselho de Ministros n. ${ }^{0}$ 54, de 16 de dezembro de 2011 (2011). Diário da República, $1^{\text {a }}$ série, n. ${ }^{0}$ 240, p. 5315.

Revista Brasileira de Políticas Públicas e Internacionais, v.3, n.2, Dezembro/2018, pp. 29-58. 